Disponível em

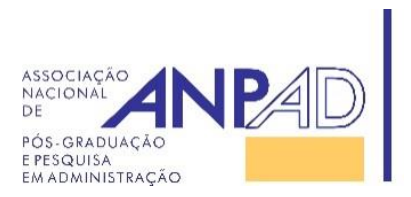

http://www.anpad.org.br/rac

RAC, Rio de Janeiro, v. 22, n. 2, art. 6, pp. 271-290, março/abril, 2018,

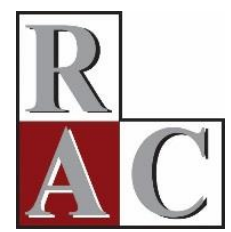

\title{
Os Conflitos sob a Mediação do Laboratório de Mudança: Uma Aprendizagem Expansiva
}

\author{
Conflicts under Change Laboratory Mediation: An Expansive Learning
}

\section{Maurício Donavan Rodrigues Paniza ${ }^{1}$ \\ Marcio Pascoal Cassandre ${ }^{2}$ Carine Maria Senger ${ }^{3}$}

Fundação Getulio Vargas, Escola de Administração de Empresas de São Paulo, São Paulo, SP, Brasil ${ }^{1}$ Universidade Estadual de Maringá, Centro de Estudos Sócio-Econômicos, Departamento de Administração,

Maringá, PR, Brasil ${ }^{2}$

Universidade Estadual do Paraná, Apucarana, PR, Brasil ${ }^{3}$

Artigo recebido em 15.08.2017. Última versão recebida em 22.12.2017. Aprovado em 18.01.2018. 


\title{
Resumo
}

Este estudo qualitativo analisa como os conflitos perpassam uma atividade de trabalho por meio da aplicação da metodologia intervencionista do Laboratório de Mudança (LM) na gestão de resíduos de um hospital-escola. À luz da Teoria da Atividade Histórico-Cultural, discutem-se os pressupostos teóricos da aprendizagem expansiva: o tipo de aprendizagem que se almeja em uma intervenção sob o LM, e os conflitos que podem emergir de tal experiência organizacional, compreendido o construto conflito em uma perspectiva epistemológica plural. A operacionalização da pesquisa deu-se mediante análise documental do registro fílmico de doze sessões do LM, em que participaram vinte trabalhadores de níveis hierárquicos diversos. A análise das sessões trouxe oito tipos diferentes de manifestações de conflitos potencialmente ampliadores da compreensão da gestão de resíduos na organização em análise. Tais conflitos, embora refletidos em situações do presente, estavam ligados às contradições históricas que atravessavam a gestão de resíduos do hospital-escola. O resultado prático é a consideração de que, quando o conflito emerge em práticas organizacionais, pode ser refletido historicamente e transversalmente à atividade, sinalizando a complexidade que cerceia a gestão e as práticas organizacionais.

Palavras-chave: conflitos; aprendizagem expansiva; laboratório de mudança; gestão de resíduos; hospital-escola.

\begin{abstract}
This qualitative study analyzes, through Change Laboratory (CL) interventionist methodology, how conflicts emerge in work activity in the waste management of a teaching hospital. We discuss the theoretical assumptions of expansive learning in light of the Cultural-Historical Activity Theory (CHAT): the type of learning desired in a CL intervention, the conflicts that can occur from such organizational experience, understanding the conflict construct from a plural epistemological perspective. The research was conducted through documental analysis of film records of twelve CL sessions, in which twenty workers from different hierarchical positions participated. Analysis of the sessions raised eight different types of conflict manifestations that can potentially amplify the comprehension of waste management in the organization analyzed. Such conflicts, although reflected in situations of the present, were connected to historical contradictions that passed throughout the waste management at the teaching hospital. The practical result is the consideration that when conflict emerges in organizational practices, it can historically and transversally reflect activity, which signals the complexity that permeates management and organizational practices.
\end{abstract}

Key words: conflicts; expansive learning; change laboratory; waste management; teaching hospital. 


\section{Introdução}

Do nascimento à morte, a vida humana é permeada pela condição de participar de inúmeras atividades, isto é, de ações que visam a um determinado objetivo. Nesse escopo, o trabalho pode ser considerado uma atividade (Engeström, 1987, 2014). Embora as atividades de trabalho tenham por prerrogativa o alcance de uma finalidade, elas nem sempre acontecem de forma harmônica, e às vezes acabam perpassadas por uma série de distúrbios que impedem os grupos de sujeitos de realizarem conjunta e plenamente suas atividades (Engeström \& Sannino, 2011).

O conflito é uma das formas pela qual podem ser percebidos os distúrbios que impedem uma equipe de trabalhadores de realizar os objetos de suas atividades (Engeström \& Sannino, 2011). No entanto, a literatura organizacional indica que os embates e os enfrentamentos entre os membros de uma organização, ainda que já tenham sido considerados essencialmente negativos, destrutivos ou prejudiciais, passaram a ser percebidos por alguns autores como um fenômeno potencialmente construtivo, tanto em termos produtivos quanto nas relações pessoais entre os membros das empresas. (Mikkelsen \& Clegg, 2017).

A participação e a cooperação nos processos decisórios e de gestão das atividades, e a percepção de si e do outro no trabalho, podem ser alternativas para lidar com os conflitos entre os trabalhadores e as respectivas equipes nas empresas, quando práticas de aprendizagem organizacional são valorizadas. No entanto, nem sempre os gestores de pessoas conseguem articular sozinhos iniciativas que contribuam para tal. Dessa forma, as intervenções propostas pela Teoria da Atividade Histórico-Cultural (TAHC) e seus métodos (Engeström, 1987, 2014) são abordagens teórico-práticas (Engeström \& Sannino, 2010; Foot, 2014) que podem contribuir para que os trabalhadores acessem tais experiências por meio da tentativa de um movimento de tempo-espaço, o qual a TAHC denomina de aprendizagem expansiva, e em que se objetiva a transformação - planejada coletivamente - de determinada atividade para uma nova forma de atividade.

Haja vista que aprender coletivamente implica muitas vezes em lidar com vozes dissonantes sobre a compreensão da atividade de trabalho e as relações que a permeiam, este artigo buscou analisar a maneira como os conflitos perpassam uma atividade coletiva de aprendizagem organizacional, por meio da aplicação da metodologia intervencionista do LM junto a um hospital-escola vinculado a uma universidade pública brasileira entre os anos de 2014 e 2016. Um pesquisador, acompanhado de um grupo de assistentes, foi convidado para realizar uma intervenção junto à atividade de gestão de resíduos. A organização vinha enfrentando desafios nesse campo, relacionados às atividades de trabalho e às necessidades específicas de descarte dos resíduos hospitalares.

Além de onerar os custos de operação do hospital, os procedimentos incorretos junto aos resíduos, no caso do descarte errado de agulhas por exemplo, colocam em risco a saúde da comunidade hospitalar. Assim, foi proposta a realização de um Laboratório de Mudança, metodologia originária da Finlândia na década de 1990. Trabalhadores dos mais diversos setores e níveis hierárquicos do hospital foram convidados a participar da intervenção, sendo que vinte deles aderiram à proposta. A intervenção foi realizada sob a forma de projeto de extensão, conectando o departamento de ensino de Administração e o hospital-escola de duas universidades públicas.

Com raízes teóricas na Teoria da Atividade Histórico-Cultural, o que difere a metodologia do Laboratório de Mudança de outras metodologias de intervenção em organizações é que, no Laboratório, busca-se construir um aprendizado denominado histórico-genético, ou seja, busca-se compreender os processos de gestão em suas origens, de uma perspectiva que enxergue o trabalho como história em movimento (Haapasaari, Engeström, \& Kerosuo, 2016; Querol, Cassandre, \& Bulgacov, 2014). Por isso, a contribuição teórica que as metodologias intervencionistas da TAHC propiciam ao campo da gestão de conflitos é a proposta de um tratamento historicamente situado para compreendê-los e enfrentá-los.

Quanto à estrutura, o trabalho divide-se em cinco tópicos, sendo este o primeiro. No segundo, apresentam-se as bases teóricas da pesquisa contemplando: os pressupostos teóricos da aprendizagem 
expansiva; o conflito como conceito, de forma a abarcar uma compreensão epistemológica plural, para que, em seguida, seja apresentado como o conflito é compreendido na TAHC. No terceiro, são abordados os artefatos metodológicos que nortearam a construção da pesquisa. No quarto, encontra-se a análise dos conflitos identificados na aprendizagem dos trabalhadores do hospital. E, no quinto, a discussão e as considerações finais.

\section{Artefatos Teóricos}

A inspiração para nominar os títulos deste e do próximo capítulo veio do conceito de mediação de Vygotsky (1978), pesquisador pioneiro na construção da TAHC. A ideia da mediação traz que os aprendizados humanos não são construídos apenas de forma biológica e individual, mas também por meio da interação social, mediada por artefatos culturais construídos coletivamente (Engeström, 2014; Engeström, Sannino, \& Virkkunen, 2014; Vygotsky, 1978).

A apresentação dos artefatos teóricos está dividida em três partes. Na primeira, discutem-se os pressupostos teóricos da aprendizagem expansiva a partir da TAHC. Na segunda, faz-se uma reflexão sobre os conflitos, contemplando as perspectivas sociológica e organizacional. Na terceira, é apresentado o significado do conflito à luz da TAHC.

\section{Bases teóricas da aprendizagem expansiva}

A TAHC, que originou o conceito de aprendizagem expansiva, foi um campo teórico construído por três gerações de pesquisadores. A $1^{\mathrm{a}}$ geração foi ancorada principalmente nos trabalhos de Lev Vygotsky; a $2^{\mathrm{a}}$ geração, capitaneada pelos trabalhos de Alexei Leontiev; e a $3^{\mathrm{a}}$ geração, com os desdobramentos contemporâneos da teoria, foi sustentada pelos trabalhos de Yrjö Engeström e os pesquisadores do Center for Research on Development, Activity and Learning (CRADLE), da Universidade de Helsinque (Engeström, 2014). No presente trabalho, o foco está na $1^{\mathrm{a}}$ e na $3^{\mathrm{a}}$ gerações.

Na primeira geração, em Vygotsky, dois conceitos são importantes. O primeiro é o de zona de desenvolvimento proximal. Entende-se que, em qualquer atividade de aprendizagem, o aprendiz já traz consigo uma aprendizagem prévia, com a qual pode tentar solucionar seus desafios de forma independente. Quando entra em interação com alguém que o está ensinando (um professor ou colega de trabalho mais experiente, por exemplo), há uma zona potencial de aprendizagem para a qual esse conhecimento pode ser ampliado (Foot, 2014; Tkachenko \& Ardichvili, 2017; Vygotsky, 1978).

O segundo conceito, por sua vez, refere-se à estimulação dupla e consiste no fato de que o primeiro estímulo já está dado, a situação-problema que o aprendiz precisa solucionar. Considerando que cada aprendiz pode vir a se utilizar de caminhos distintos para solucionar seus desafios cotidianos, o segundo estímulo consiste na oferta de artefatos, instrumentos e ferramentas por meio dos quais o sujeito pode ampliar sua compreensão sobre a tarefa ou a atividade que está realizando (Engeström, Kajamaaa, \& Nummijoki, 2015; Laitinen, Sannino, \& Engeström, 2016; Sannino \& Engeström, 2017; Sannino \& Laitinen, 2015; Vygotsky, 1978). Ao ampliar sua compreensão, os sujeitos conseguem agir intencionalmente para romper com situações conflituosas, lidando com os problemas que precisam ser solucionados (Engeström et al., 2014).

Outro ponto que orienta os princípios da teoria está ligado à busca de uma perspectiva genética, ou seja, não interessa à teoria compreender apenas como estão dados os fenômenos sociais, mas compreendê-los em suas origens e movimentos históricos (Engeström, 2014; Haapasaari et al., 2016, Sannino, Engeström, \& Lahikainen, 2016). Por isso, por mais que as situações vivenciadas por um grupo de aprendizes possam ser tomadas por reflexão em outros contextos, ao se adotar o background da TAHC é importante demarcar a singularidade das experiências de aprendizagem organizacional, cada qual com suas respectivas geografias e tempos históricos. 
No que diz respeito à metáfora da expansão para a aprendizagem organizacional (Engeström, 1987, 2014), conforme Querol, Cassandre e Bulgacov (2014), ela está ligada à criação de novas formas de organização e ferramentas ao redor de um determinado objeto, em processos que compreendem a zona de desenvolvimento proximal e a estimulação dupla de Vygotsky. Nesse processo de aprendizes, os sujeitos contam com a coordenação de um pesquisador, denominado intervencionista, cuja função no processo de aprendizagem é pedagógica.

O foco das pesquisas em aprendizagem expansiva, conforme explicam Engeström e Sannino (2010), está na compreensão de como os sujeitos de uma atividade passam da condição de aprendizes individuais para um processo de construção coletiva, cujo resultado final seja a transformação dessa atividade. No entanto, esse desejo de transformação é uma condição e uma reivindicação dos próprios sujeitos da atividade (Sannino, Engeström, \& Lemos, 2016), que passam a questionar as formas como essa atividade está atualmente organizada e, com isso, compreendem coletivamente a necessidade de realizar mudanças. Para que haja a expansão, a metodologia prevê o envolvimento dos aprendizes nas sete fases de um ciclo que compreende ações de construção coletiva (Engeström, 2014; Engeström, Rantavuori, \& Kerosuo, 2013).

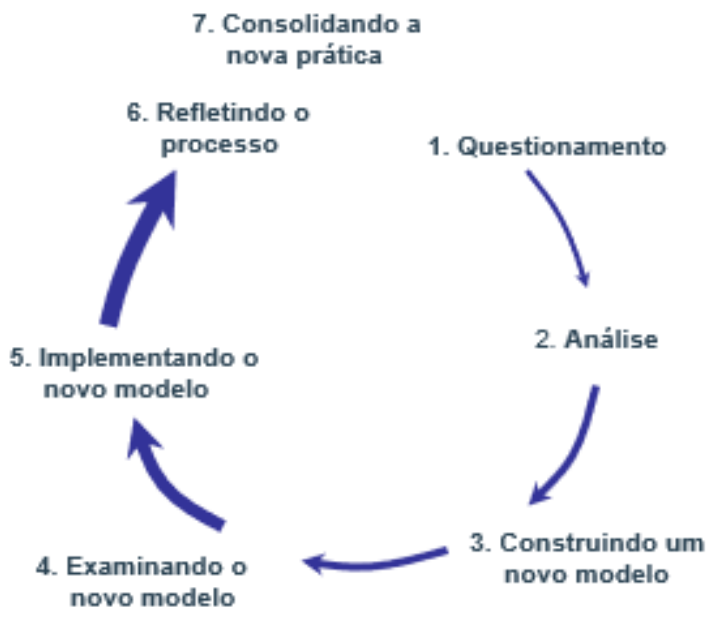

Figura 1. Ciclo de Aprendizagem Expansiva

Fonte: Adaptado de Engeström, Y. (2014). Learning by expanding (2nd ed.). New York: Cambridge University Press.

A fase 1 - Questionamento, compreende uma movimentação coletiva e institucional para dizer que as práticas organizacionais atuais são insuficientes para atender o objeto (motivo, finalidade) da atividade de trabalho. Na fase 2 - Análise da situação atual, há um exercício de compreensão de como a atividade se desenvolveu historicamente até chegar à sua forma atual. Na fase 3 - Construindo um novo modelo, os aprendizes rascunham uma ideia que ofereça uma solução para a forma atual insatisfatória de realização da atividade, a qual deve ser testada previamente em um pequeno espaço da organização.

$\mathrm{Na}$ fase 4 - Exame do novo modelo, os aprendizes apreciam o novo conceito proposto para atividade, compreendendo seu funcionamento e seus limites. Nas fases 5 e 6 , os aprendizes implantam o novo modelo para a atividade e refletem o processo realizado. No fim do ciclo de expansão, na fase 7 , decidem se o modelo de reorganização da atividade deu certo no ambiente menor em que foi implantado e, com isso, é possível ter-se uma prática concreta a ser disseminada em toda a organização.

$\mathrm{Na}$ prática de aprendizagem expansiva, há diversas metodologias coletivas que podem ser realizadas em contextos de trabalho (Engeström \& Sannino, 2016). Entre elas está o Laboratório de Mudança (LM). A base teórica central da intervenção do LM está na estimulação dupla de Vygotsky. Em um contexto de intervenção formativa do LM, os trabalhadores encontram-se diante de uma situação-problema que atua como primeiro estímulo. O segundo estímulo parte do trabalho do pesquisador intervencionista de fomentar nesses trabalhadores a possibilidade de eles se apropriarem de artefatos secundários que os auxiliem a pôr em prática seu poder de agência e volição para mudar a 
situação-problema (Engeström \& Sannino, 2016; Haapasaari et al., 2016; Sannino, 2015; Sannino \& Engeström, 2017). Um dos artefatos secundários utilizados nas intervenções é o sistema de atividade.

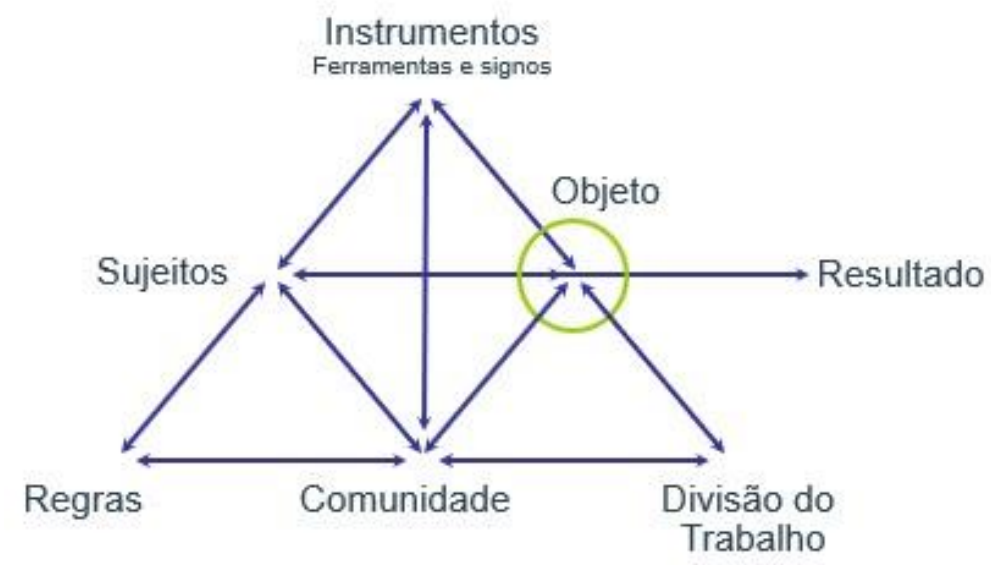

Figura 2. Estrutura de um Sistema de Atividade em uma Atividade de Aprendizagem

Fonte: Adaptado de Engeström, Y. (2014). Learning by expanding (2nd ed.). New York: Cambridge University Press.

O sistema de atividade, de caráter heurístico, funciona como artefato de reflexão da atividade ao permitir a realização de análises macro e micro contextuais do trabalho, incorporando a possibilidade de compreendê-lo em seus aspectos objetivos e subjetivos. No contexto do LM apresentado nesta pesquisa, o sistema de atividade foi incorporado como subsídio para compreensão do passado, do presente e da perspectiva futura da atividade, permitindo uma experiência transversal e dialógica de aprendizagem. Operacionalmente, o LM é desenvolvido em um tempo de até 12 sessões de aproximadamente duas horas, que podem ocorrer semanalmente e, em seguida, são realizadas algumas reuniões para acompanhamento das ações que os próprios participantes resolverem levar adiante no local da intervenção (Virkkunen \& Newham, 2015). Nesta pesquisa, o corpus de análise está circunscrito pela fase de realização das 12 sessões, que compreende o ciclo expansivo das fases 1 a 4 , quando os trabalhadores tentaram testar e implementar um novo modelo proposto para a atividade de gestão de resíduos.

\section{Debates e reflexões sobre o conflito: da sociedade às atividades de trabalho}

O construto teórico conflito, antes de interessar ao contexto da gestão, foi objeto de investigação de autores seminais na Teoria Social. O debate inicial sociológico está centrado no escopo macroestrutural (Giddens \& Sutton, 2016). Na obra de Marx, a Teoria do Conflito Social (Marx, 2013) explica o conflito a partir da oposição de interesses entre as classes sociais, nas relações entre produção e força de trabalho.

Já na perspectiva weberiana, o conflito social não se circunscreve apenas a termos de conflitos de classe, mas se entende ao conflito como algo inerente às ações sociais, haja vista que os homens se enfrentam pela posse de recursos, que não estão disponíveis para todos. Por isso, pode-se relacionar essa perspectiva com a Teoria da Burocracia e a necessidade percebida pelo autor de que haja impessoalidade na gestão. Assim, infere-se o potencial atenuador da gestão burocrática para com os conflitos entre os homens (Weber, 1978).

Por sua vez, também se destaca no campo da Sociologia do Conflito o pensamento de Georg Simmel, com "uma visão da experiência humana como marcada pela criatividade, pela fragmentação e pelo conflito" (Levine, 2015, p. 37). Simmel (1971) entende a relação do conflito com potencial tanto positivo quanto negativo; no entanto, embora seja possível fazer a distinção do ponto de vista teórico, de forma empírica essa dissociação é impossível para o autor. Em que pese a apreciação positiva, o sociólogo considera que, paradoxalmente, ainda que o conflito tenha por objetivo solucionar posições divergentes, de alguma maneira o resultado obtido é de um resultado unitário. $\mathrm{O}$ aspecto negativo vem 
do fato de que essa unidade estabelecida pode ser de manutenção das duas partes, ou da derrocada de uma ou de outra.

A defesa de Simmel sobre a impossibilidade de se dissociarem empiricamente os aspectos positivos e os negativos do conflito está expressa na ideia de que "um grupo absolutamente centrípeto e harmonioso, uma 'unificação' pura, não só é empiricamente irreal, não podendo mostrar nenhum processo da vida real" (Simmel, 1971, p. 72, tradução nossa). É justamente essa ambiguidade entre as percepções negativa, positiva, ou ambas, que pode ser percebida quando o conceito passa a interessar ao campo da gestão.

Essa encruzilhada teórica, em que a visão do conflito organizacional transita entre o caráter negativo e o positivo, foi analisada por Mikkelsen e Clegg (2017). A partir de uma análise genealógica acerca do conceito (Tabela 1), eles perceberam que é entre as décadas de 1950 e 1970 que os teóricos organizacionais passam a deslocar o sentido do conflito de uma visão disfuncional (caráter negativo) para a funcional (caráter positivo).

Porém, diante da literatura sobre conflito organizacional levantada, questiona-se a suposta essência para o termo. Nessa perspectiva, o conflito como conceito unificado foi questionado a partir da contestação de três tendências: (a) essência funcional (positivo e negativo); (b) amplitude (diádico e organizacional); e (c) gestão e resolução (normativo e prescritivo). A partir dessas tendências, a contestação do conflito como conceito essencial é apresentada em um quadro teórico, em que se propõe que "a teorização do conflito pode se beneficiar de uma prática Re(construtiva)-reflexiva" (Mikkelsen \& Clegg, 2017, p. 6, tradução nossa).

Tabela 1

\section{Concepções Essencialmente Contestadas de Conflito na Pesquisa Organizacional}

\begin{tabular}{|c|c|c|c|}
\hline Concepção & Posições assumidas & Objetivos & Principais conceitos \\
\hline $\begin{array}{l}\text { Conflito como um } \\
\text { fenômeno comportamental } \\
\text { distinto }\end{array}$ & $\begin{array}{l}\text { · é disfuncional; } \\
\text { - destrói relacionamentos; } \\
\text { · manifesta-se no } \\
\text { comportamento como } \\
\text { interferência deliberada } \\
\text { ou oposição; } \\
\text { - abala o equilíbrio das } \\
\text { organizações. }\end{array}$ & $\begin{array}{l}\text { Normativo: } \\
\text { reduzir o nível de conflito }\end{array}$ & $\begin{array}{l}\cdot \text { comportamento } \\
\cdot \text { interferência } \\
\cdot \text { incompatibilidade de } \\
\text { objetivos }\end{array}$ \\
\hline $\begin{array}{l}\text { Conflito como meio } \\
\text { instrumental }\end{array}$ & $\begin{array}{l}\text { · é categorizado pelo seu } \\
\text { conteúdo; } \\
\text { · o conflito negativo } \\
\text { prejudica a organização; } \\
\text { · o conflito positivo } \\
\text { beneficia a organização; } \\
\text { · é interpessoal; } \\
\text { · é reconhecido e } \\
\text { verbalizado; } \\
\text { · pode ser reduzido ou } \\
\text { estimulado, dependendo } \\
\text { do resultado pretendido. }\end{array}$ & $\begin{array}{l}\text { Normativo: } \\
\text { obter conflitos produtivos }\end{array}$ & $\begin{array}{l}\cdot \text { conflito de tarefa } \\
\cdot \text { conflito de } \\
\text { relacionamento } \\
\cdot \text { conflito de processos } \\
\cdot \text { conflito de status } \\
\cdot \text { conflito de estilos de } \\
\text { gestão }\end{array}$ \\
\hline
\end{tabular}


Tabela 1 (continuação)

\begin{tabular}{|c|c|c|c|}
\hline Concepção & Posições assumidas & Objetivos & Principais conceitos \\
\hline $\begin{array}{l}\text { Conflito como construção } \\
\text { social }\end{array}$ & $\begin{array}{l}\text { · é onipresente; } \\
\text { · é moldado pela definição } \\
\text { que o observador dá a } \\
\text { ele; } \\
\text { · é constituído pela } \\
\text { comunicação; } \\
\text { · é moldado pelo discurso; } \\
\text { · está incorporado nas } \\
\text { interações humanas; } \\
\text { · parte da textura social } \\
\text { nas organizações; } \\
\text { · são processos que não } \\
\text { são necessariamente } \\
\text { visíveis, reconhecidos ou } \\
\text { verbalizados. }\end{array}$ & $\begin{array}{l}\text { Descritivo: } \\
\text { entender as dinâmicas do } \\
\text { conflito }\end{array}$ & $\begin{array}{l}\cdot \text { significado } \\
\cdot \text { experiência } \\
\cdot \text { contexto cultural } \\
\cdot \text { contexto estrutural } \\
\cdot \text { contexto integrado } \\
\cdot \text { discurso } \\
\cdot \text { enquadramento } \\
\cdot \text { comunicação }\end{array}$ \\
\hline
\end{tabular}

Nota. Fonte: Adaptado de Mikkelsen, E. N., \& Clegg, S. (2017, June 29). Conceptions of conflict in organizational conflict research: Toward critical reflexivity (p. 7). Journal of Management Inquiry (ahead of print). http://dx.doi.org/10.1177/1056492617716774

Reconhecidas as narrativas que o conflito assume na pesquisa organizacional, o próximo tópico discute a compreensão do conflito frente à TAHC. A reflexão, assim como em Mikkelsen e Clegg (2017), será inspirada pela teorização organizacional conjuntiva (Tsoukas, 2017), que recusa a compreensão das organizações de uma perspectiva teórica simplificadora, reconhecendo a complexidade pela qual as organizações são construídas e constituídas. O pensamento conjuntivo, segundo Tsoukas (2017, p. 143, tradução nossa), pode contribuir para "encontrar caminhos de conexão e, então, de acumulação, para tanto as experiências dos membros da organização quanto do comportamento organizacional em geral".

Em contexto nacional, a literatura sobre conflito também sinaliza a complexidade que envolve a compreensão sobre os conflitos nas organizações. Sob a perspectiva micro contextual da gestão de pessoas, conforme A. R. L. Silva, Junquilho e Carrieri (2008), entende-se que, apesar da pretensa intenção de convergência entre atores e interesses nas empresas, as práticas e as políticas da área "devem ser recontextualizadas com base no reconhecimento de que remetem à integração e à fragmentação organizacional, inseridas em processo de mediação das diferenças reconstruídas socialmente" (p. 12). Nessa perspectiva, também se faz pertinente expandir as possibilidades de análises, apreendendo o conflito "como espaço para reflexão e mudança na perspectiva de significado da vida das pessoas dentro e fora da organização" (A. B. Silva \& Rossetto, 2010, p. 44). As metodologias intervencionistas da TAHC incorporam essas possibilidades ao proporcionarem uma experiência coletiva e reflexiva daquilo que se impõe como distúrbio no desenvolvimento de uma atividade de trabalho.

\section{Os conflitos como fonte de aprendizagem no trabalho: a perspectiva da Teoria da Atividade}

Antes de delimitar o conflito, que é uma unidade menor na lógica dialética que permeia a Teoria da Atividade, é preciso compreender as contradições, pois o primeiro é uma manifestação presente das segundas, que são históricas. Para explicar o conceito de contradição nas atividades, Engeström (2014) volta-se para o sistema produtivo capitalista, apontando que a primeira contradição que impede uma atividade de ser realizada plenamente está no embate entre o valor de uso e o valor de troca, pois o segundo se sobrepõe ao primeiro. Depois, as outras contradições vão se desvelando para o contexto interno do sistema produtivo, colocando os trabalhadores face a muitas situações desafiadoras. 
Ao propor uma teoria cuja finalidade é a expansão de um aprendizado, há que se considerar que as atividades em que esses aprendizes estão imersos foram construídas histórica e culturalmente. É por isso que o construto da contradição está presente na Teoria da Atividade, porque, conforme Engeström e Sannino (2011), ele é uma peça central para compreender as transformações pelas quais as organizações passam no decorrer do tempo. Além disso, Foot (2014) ressalta que as contradições podem ser vistas como fontes de desenvolvimento, porque, ao estremecerem o funcionamento dos sistemas sociais, as contradições abrem possibilidades aos agentes para inovações e criatividade, bem como à necessidade de que os aprendizes busquem novos sentidos e novas formas de organizar e perceber coletivamente a atividade.

Os autores refletem que as contradições são apresentadas, muitas vezes, de forma muito vaga pelo campo dos negócios, como se significassem apenas relações de oposição ou de embates entre os membros da organização no tempo presente. Por isso, segundo eles, há uma apropriação equivocada do conceito, pois qualquer disfunção identificada na organização é chamada pelos gestores e executivos como sinônimo de contradição. Defende-se, portanto, uma orientação teórica clara para o entendimento da palavra, que não considere a contradição apenas uma forma módica de designar problemas cotidianos que afetem o desempenho organizacional (Engeström \& Sannino, 2011).

O tratamento da contradição no sentido de problemas pontuais de desempenho e conflitos de papéis nas organizações, no sentido do parágrafo anterior, também revela um tratamento a-histórico da questão, o que Engeström e Sannino (2011) criticam, ao indicarem que alguns autores trataram a contradição como um fenômeno considerando apenas a consequência da atividade de organizar, sem vincular esses processos às formações culturais, históricas e econômicas em que essas atividades estiveram inseridas.

Partindo dessas críticas para a compreensão da contradição, Engeström e Sannino (2011) teorizam que as contradições, enquanto elementos que impedem o desenvolvimento pleno de uma atividade humana, não podem ser observadas diretamente, pois elas são históricas, emergentes e sistêmicas. Por isso, não é possível a sua delimitação em termos de uma experiência subjetiva única ou como um aspecto situacional momentâneo. As contradições só se tornam reconhecidas por meio da reconstrução verbal e da iniciativa daqueles que estão envolvidos na atividade. Quando os sujeitos se envolvem em uma experiência dialógica e histórica de compreensão da atividade, as contradições emergem, não como um construto fechado e único, mas a partir de suas manifestações, e como incentivo à ação e reação (Sannino \& Engeström, 2017).

Desta forma, os autores identificaram os tipos de manifestações discursivas a partir de evidências linguísticas que indicam a emergência das contradições de um sistema de atividade. Conforme Engeström e Sannino (2011), entre as possíveis manifestações das contradições estão os conflitos e os conflitos críticos, cujos conceitos estão sintetizados na Tabela 2. 
Tabela 2

Conflitos como Manifestações Discursivas da Contradição

\begin{tabular}{|c|c|c|c|}
\hline Manifestação & Características & Pistas Linguísticas & $\begin{array}{l}\text { Vínculos com as narrativas } \\
\text { de Mikkelsen e Clegg (2017) }\end{array}$ \\
\hline Conflito & $\begin{array}{l}\text { Arguição, crítica, } \\
\text { discordância e resistência } \\
\text { Resolução: } \\
\text { Encontrando um } \\
\text { compromisso ou submetendo- } \\
\text { se à autoridade ou maioria. }\end{array}$ & $\begin{array}{l}\text { Não } \\
\text { Eu discordo. } \\
\text { Isso não é verdade. } \\
\text { Sim } \\
\text { Isto eu posso aceitar. }\end{array}$ & \multirow{2}{*}{$\begin{array}{l}\text { comportamental: oposição, } \\
\text { crítica, contrariedade. } \\
\text { instrumental: reconhecer as } \\
\text { autoridades, submeter-se à } \\
\text { maioria, comprometer-se. } \\
\text { construção social: criar um } \\
\text { novo senso pessoal, negociar } \\
\text { um novo significado. }\end{array}$} \\
\hline Conflito crítico & $\begin{array}{l}\text { Em face de motivos } \\
\text { contraditórios na interação } \\
\text { social, há um sentimento de } \\
\text { violação ou culpa. Há uma } \\
\text { paralisia impossível de ser } \\
\text { resolvida sozinha pelo } \\
\text { indivíduo. } \\
\text { Resolução: } \\
\text { Encontro de um novo senso } \\
\text { pessoal e negociando um } \\
\text { novo significado }\end{array}$ & $\begin{array}{l}\text { Estruturas narrativas com } \\
\text { cargas pessoais, emocionais e } \\
\text { morais. } \\
\text { Metáforas }\end{array}$ & \\
\hline
\end{tabular}

Nota. Fonte: Adaptado de Engeström, Y., \& Sannino, A. (2011). Discursive manifestations of contradictions in organizational change efforts: A methodological framework. Journal of Organizational Change Management, 24(3), 368-387. http://dx.doi.org/10.1108/09534811111132758 e Mikkelsen, E. N., \& Clegg, S. (2017, June 29). Conceptions of conflict in organizational conflict research: Toward critical reflexivity (p. 7). Journal of Management Inquiry (ahead of print). http://dx.doi.org/10.1177/1056492617716774

Enquanto os conflitos podem ser percebidos em determinadas situações, as contradições precisam de uma apreciação histórica englobando os desafios e as transformações que impactam uma atividade (Cassandre \& Godoi, 2014; Haapasaari et al., 2016; Kaatrakoski, Littlejohn, \& Hood, 2017). Justamente são as manifestações das contradições da atividade por meio dos conflitos que atentam para a necessidade de compreender o ciclo teórico da aprendizagem expansiva como algo não harmonioso, pois, considerando a autonomia e a autorregulação esperadas dos grupos trabalhados sob os princípios da metodologia intervencionista do LM, pode ser que um grupo não consiga se desenvolver de uma fase para outra, ou até mesmo que grupos regridam na transição, ou não consigam passar de determinada fase do ciclo expansivo.

De toda forma, os elementos analíticos do sistema de atividade contribuem como artefatos mediadores para o emergir de tais conflitos da atividade, que se manifestam nas falas e nas memórias dos aprendizes. A partir dessas manifestações, nem sempre convergentes, os aprendizes são postos à possibilidade de exercer seu poder de agência (Vänninen, Querol, \& Engeström, 2015), ressignificando e reconstruindo as práticas de trabalho, tendo a possibilidade de superar tais conflitos, ou quando da impossibilidade de superação, pelo menos tendo condições de enfrentá-los.

\section{Artefatos Metodológicos}

A pesquisa realizada teve abordagem qualitativa, a partir das premissas de autenticidade, em que há presença do autor (o autor esteve lá) em campo, em interação direta com os sujeitos de pesquisa; plausibilidade, apresentando uma narrativa que produz sentido oferecendo um resultado concreto ao leitor; e criticidade, haja vista que a narrativa almeja que os leitores repensem premissas dadas como certas, refletindo outras possibilidades e alternativas (Pozzebon \& Petrini, 2013). A importância de 
pensar em tais critérios para apreciação de pesquisas qualitativas, conforme Pozzebon e Petrini (2013), está no fato de que, embora pesquisas de natureza crítico-interpretativa tendam a ter epistemologias construtivistas, como na abordagem histórico-cultural em voga nesta pesquisa, é preciso que haja um conjunto de ferramentas de avaliação metodológica. Tal aparato é pertinente para a construção de uma tradição sólida de pesquisa, porque as abordagens qualitativas são ainda emergentes e minoritárias em algumas áreas.

Em termos específicos, o trabalho está calcado em uma epistemologia qualitativa (González Rey, 2005), marcada pelo singular reconhecido como científico, a partir da compreensão de que a pesquisa científica é, ao mesmo tempo, comunicação e diálogo, cuja "significação epistemológica está estreitamente relacionada ao valor teórico da subjetividade no estudo do homem, a cultura e a sociedade, dimensões que se constituem, de forma permanente entre si" (González Rey, 2005, p. 13). A singularidade do conhecimento produzido é uma das principais características da epistemologia da TAHC. Ainda que as intervenções sejam orientadas pelo uso de artefatos mediadores semelhantes estímulo duplo - como o sistema de atividade, os resultados de pesquisa não são homogêneos, tampouco generalizáveis.

Engeström (2014) sinaliza que, se as ferramentas da TAHC forem compreendidas apenas como sequências idealizadas, elas serão consideradas estritamente prescritivas. No entanto, o autor enfatiza o caráter singular e historicamente situado do conhecimento produzido ao explicar que: "os processos de aprendizagem humana são muito diversos e estão continuamente se transformando. Não há um caminho único, universal, biologicamente determinado, apropriado ou de melhor direção para aprender entre humanos" (Engeström, 2014, p. 18, tradução nossa).

Assim, a operacionalização deste estudo ocorreu a partir de uma pesquisa documental nos dados registrados durante as sessões do LM desenvolvidas em um hospital universitário, cuja ação foi uma demanda do Grupo Gestor de Resíduos Sólidos (GGRS) - uma instância administrativa multiprofissional para gestão de resíduos hospitalares - na intenção de resolver um conflito inicial existente de que funcionários, pacientes e seus acompanhantes estariam descartando de maneira equivocada os resíduos sólidos (comum, reciclado e contaminado) gerados na atividade. Desta forma, destaca-se que não foram os pesquisadores que escolheram o hospital, mas sim foi o hospital que escolheu os pesquisadores, considerando que estes estudam metodologias intervencionistas, dentre as quais, o LM.

Nesse sentido, é importante observar que o intervencionista e seus assistentes não tinham nenhum vínculo com o hospital universitário no momento em que foram contatados para aplicar a metodologia. Contudo, salienta-se que, no decorrer da implementação das sessões, o intervencionista passou a integrar o corpo docente da universidade à qual o hospital é vinculado, num processo de remoção interna entre universidades estaduais.

As doze sessões do LM foram realizadas à luz das premissas teóricas da TAHC, compreendendo as fases do ciclo de aprendizagem expansiva, que partiu do questionamento do formato atual da gestão de resíduos até a tentativa de criação e formatação de um novo modelo de trabalho para a atividade (Engeström et al., 2013). As sessões foram registradas integralmente em formato audiovisual e, posteriormente, transcritas. Cada sessão contemplou um tempo aproximado de duas horas. De forma a atender os pressupostos éticos (Heath, Hindmarsh, \& Luff, 2010) na pesquisa com registro de material audiovisual, solicitou-se aos participantes do LM a autorização para que as sessões fossem gravadas. Diante da autorização dos sujeitos da pesquisa para o registro fílmico, eles foram informados de que o conteúdo só seria utilizado em situações internas de pesquisa e que, no caso de divulgação pública dos resultados da pesquisa, as identidades dos participantes seriam preservadas.

A pesquisa documental com audiovisual revelou-se necessária por conta da importância de retornar várias vezes a eventos que teriam ocorrido no passado. Além disso, conforme Loizos (2008), os vídeos são registros materiais e concretos de acontecimentos da vida, podendo servir, portanto, de fonte à pesquisa. Garcez, Duarte e Eisenberg (2011) ainda argumentam que o uso de material 
audiovisual na pesquisa qualitativa permite captar aspectos do campo que o pesquisador dificilmente conseguiria captar partindo de outros recursos.

Na Tabela 3, é apresentado o perfil dos sujeitos participantes da pesquisa, cujas interações foram registradas e documentadas. A composição dos aprendizes em sua maior parte por trabalhadores operacionais se deu porque, no cotidiano de trabalho, são as pessoas que mais têm contato com os resíduos produzidos pelo hospital. Observa-se que a seleção dos participantes do LM ocorreu por meio de indicação do GGRS, de maneira a contemplar todos os níveis, considerando também aqueles que, de uma forma ou de outra, estavam envolvidos naquela gestão. Os participantes foram convidados a aderir voluntariamente ao LM.

Tabela 3

\section{Perfil Profissional dos Participantes do Laboratório de Mudança}

\begin{tabular}{lll}
\hline Nível/Função & Quantidade & Tempo de Serviço \\
\hline Operacional & 10 & Máximo: \\
- Auxiliar de Enfermagem & & 26 anos \\
- Auxiliar Operacional & & Mínimo: \\
& & 6 anos \\
\hline Médio e Técnico & 4 & Máximo: \\
- Técnico Administrativo & & 10 anos \\
- Técnico de Enfermagem & & Mínimo: \\
- Técnico de Laboratório & & 5 anos \\
\hline Superior & 6 & Máximo: \\
- Administrador & & 22 anos \\
- Bioquímico & Mínimo: \\
- Enfermeiro & 5 anos \\
- Engenheiro Químico & \\
\hline
\end{tabular}

Nota. Fonte: elaborada pelos autores.

Após os registros fílmicos (que totalizaram 26 horas e 25 minutos), os dados das sessões do LM foram integralmente transcritos, resultando em 414 páginas de dados brutos. Para a análise destes, utilizou-se o software NVivo. Em análise primária, partiu-se das evidências discursivas (Engeström \& Sannino, 2011) que poderiam caracterizar as manifestações de conflito, em situações de negação, oposição, discordância ou resistência.

Para a apresentação e a análise dos dados, haja vista a amplitude do corpus, foram priorizados os significados e as interpretações das manifestações de conflito no trabalho no escopo do grupo, em detrimento das interações diádicas ou manifestações individuais. Assim, serão sumarizados os principais conflitos emergentes na experiência de aprendizagem na atividade de gestão de resíduos vivenciada pelos trabalhadores do hospital-escola.

\section{Os Conflitos Emergentes na Experiência de Aprendizagem Expansiva na Gestão de Resíduos}

No decorrer das 12 sessões do LM, os trabalhadores do hospital-escola foram envolvidos com o ciclo de aprendizagem expansiva, partindo do questionamento da organização presente na gestão de resíduos. Em seguida, na fase de Análise, com a ajuda dos estímulos duplos ofertados pelo pesquisador 
intervencionista, como a realização de entrevistas com os pares no local de trabalho e a interação com as práticas de outras organizações hospitalares, foi construída uma trajetória histórica da atividade de gestão de resíduos, de modo que os trabalhadores pudessem ter uma percepção de como a atividade havia sido construída no passado até os dias presentes.

Com essa compreensão do passado e do presente, os aprendizes chegaram à fase de Proposta e Exame de um novo modelo de trabalho, cuja decisão coletiva foi a de transformar a atividade de gestão de resíduos do hospital em um serviço que tivesse um gestor com dedicação exclusiva. No entanto, a trajetória construída pelo grupo demonstrou que os conflitos foram centrais para a aprendizagem ocorrida. Essas manifestações são apresentadas na Tabela 4.

Tabela 4

\section{Sumarização dos Principais Conflitos Emergentes no Laboratório De Mudança}

\begin{tabular}{lll}
\hline Conflitos & Significados e Manifestações & Conexão com a história da atividade \\
\hline $\begin{array}{l}\text { O novo e o velho modelos } \\
\text { de gestão dos resíduos }\end{array}$ & $\begin{array}{l}\text { "Antes eu fazia a gestão de resíduos } \\
\text { de outra maneira, agora não sei como } \\
\text { fazer.” }\end{array}$ & $\begin{array}{l}\text { O contraste entre passado e presente } \\
\text { fatores técnicos, legais, comportamentais }\end{array}$ \\
& $\begin{array}{l}\text { e relacionais que ocasionam distúrbios no } \\
\text { cotidiano da atividade. A comparação da }\end{array}$ \\
& forma como se fazia a atividade no \\
& passado com a forma como se faz agora \\
& mostra que gerir resíduo está cada vez \\
& mais difícil e complexo.
\end{tabular}

\begin{tabular}{|c|c|c|}
\hline $\begin{array}{l}\text { e propostas de } \\
\text { va solução para os }\end{array}$ & $\begin{array}{l}\text { "A solução mais rápida está em mim } \\
\text { ou no meu setor." }\end{array}$ & Desabafos sobre \\
\hline
\end{tabular}

\begin{tabular}{|c|c|c|}
\hline $\begin{array}{l}\text { Qualidade da } \\
\text { comunicação }\end{array}$ & $\begin{array}{l}\text { "Eu acredito que a gestão de resíduos } \\
\text { é de uma maneira, mas não tenho } \\
\text { certeza, pois a forma correta de fazer } \\
\text { tem mudado constantemente." }\end{array}$ & $\begin{array}{l}\text { Análise coletiva da atividade: “Como nós } \\
\text { trabalhávamos no passado?" Revisita as } \\
\text { legislações da gestão de resíduos e a } \\
\text { dinâmica de transformação dos } \\
\text { procedimentos internos. }\end{array}$ \\
\hline $\begin{array}{l}\text { Entre os processos de } \\
\text { agentividade e de } \\
\text { passividade }\end{array}$ & $\begin{array}{l}\text { "Eu acho que o meu procedimento } \\
\text { no dia a dia é irrelevante e não me } \\
\text { sinto responsável. Eu estou } \\
\text { aborrecido, sinto sono e fico em } \\
\text { silêncio. Mas posso escolher me } \\
\text { comprometer individualmente com a } \\
\text { gestão de resíduos coletiva." }\end{array}$ & $\begin{array}{l}\text { O reexame do passado da atividade gera } \\
\text { resistência e pessimismo para possíveis } \\
\text { contribuições dos trabalhadores do } \\
\text { hospital sobre o futuro da atividade, mas } \\
\text { também conscientiza sobre as } \\
\text { possibilidades individuais de ação. }\end{array}$ \\
\hline Reivindicação por atenção & $\begin{array}{l}\text { "Eu só consigo discordar, ironizar e } \\
\text { provocar o comentário do outro. Não } \\
\text { faço contribuições construtivas." }\end{array}$ & $\begin{array}{l}\text { O exame do presente gera ceticismo e } \\
\text { pessimismo. O futuro desejado é } \\
\text { impossível, pois não contempla o que } \\
\text { alguns participantes pensam. }\end{array}$ \\
\hline Mérito & $\begin{array}{l}\text { "Estou aqui há mais tempo, conheço } \\
\text { a gestão de resíduos há mais tempo. } \\
\text { Sei mais que os meus colegas. Então } \\
\text { preciso ser mais ouvido." }\end{array}$ & $\begin{array}{l}\text { Ao retroceder ao passado da atividade, o } \\
\text { grupo percebe que alguns participantes } \\
\text { têm mais conhecimento técnico sobre a } \\
\text { questão. Há uma dinâmica interna de que, } \\
\text { por esse motivo, as contribuições dessas } \\
\text { pessoas teriam mais importância. }\end{array}$ \\
\hline
\end{tabular}


Tabela 4 (continuação)

\begin{tabular}{lll}
\hline Conflitos & Significados e Manifestações & Conexão com a história da atividade \\
\hline $\begin{array}{l}\text { Diferentes posições } \\
\text { hierárquicas }\end{array}$ & $\begin{array}{l}\text { "O conhecimento do trabalhador de } \\
\text { nível operacional vale x, de nível } \\
\text { médio 2x, de nível superior 4x." }\end{array}$ & $\begin{array}{l}\text { O contraste entre passado e presente } \\
\text { evidenciou que, por mais que as } \\
\text { contribuições de trabalhadores } \\
\text { operacionais fossem coerentes, elas não } \\
\text { eram ouvidas ou simplesmente ignoradas. }\end{array}$ \\
\hline $\begin{array}{l}\text { Particularidades do } \\
\text { funcionamento de uma } \\
\text { organização pública. }\end{array}$ & $\begin{array}{l}\text { "Como podemos mudar a gestão de } \\
\text { resíduos se a nossa autonomia para } \\
\text { mudar procedimentos de gestão é } \\
\text { limitada?" }\end{array}$ & $\begin{array}{l}\text { O grupo enxerga inúmeras alternativas } \\
\text { para possibilitar melhorias incrementais e } \\
\text { relacionais da atividade. Mas acaba } \\
\text { limitado, seja pelo contexto legal, seja } \\
\text { pelos procedimentos internos de gestão. }\end{array}$ \\
\hline
\end{tabular}

Nota. Os Significados e Manifestações indicados não representam falas literais individuais, mas correspondem aos sentidos verbalizados pelo grupo ou alguns membros do grupo. Portanto, são representativos da coletividade de sujeitos da pesquisa. Fonte: Dados da pesquisa, adaptada de Engeström, Y. (2014). Learning by expanding (2nd ed.). New York: Cambridge University Press.

Inicialmente, ao descreverem as dificuldades nos procedimentos em gestão de resíduos, os trabalhadores pronta e simultaneamente apontavam uma solução imediata, porém em nível individual, baseada em suas experiências. Entretanto, nem todas soluções ou melhorias propostas na fase de Questionamento atenderam de forma satisfatória todos os setores representados no LM. Esse exercício reflexivo inicial, portanto, foi subsídio para que os participantes pudessem se escutar e compreender as especificidades do trabalho uns dos outros, e para que começassem a entender coletivamente a situação do resíduo tal como prevê a teoria da aprendizagem expansiva. Ou seja, a compreensão coletiva da mudança sai do entendimento do indivíduo, localizado dentro de um setor da organização, para um nível coletivo, no qual o compartilhamento de diferentes visões de indivíduos de diferentes setores é um estímulo para a transformação da atividade, conforme estabelecido por Engeström e Sannino (2010).

Com a multiplicidade de visões sobre as necessidades de melhorias na atividade e a entrada na reconstrução histórica da gestão de resíduos desde que o hospital havia sido criado, em 1989, percebeuse a ocorrência de distúrbios na comunicação interna. A informação das regras de como lidar com as situações não é explícita. Mesmo havendo procedimentos padrões formalizados por força da lei, os participantes manifestaram um descontentamento com a atual maneira estabelecida de cumprir tais procedimentos, tanto entre os trabalhadores de níveis superior, médio e operacional, quanto os recémchegados. Por outro lado, em um período de história de pouco mais de 20 anos, o objeto da atividade (gerenciamento de resíduos) muda rapidamente, e os trabalhadores não acompanham tais demandas por mudanças no mesmo ritmo em que estas acontecem.

O conflito resultante da insuficiência de comunicação, ou pelas definições que os trabalhadores dão a ela dentro dos níveis mencionados, indicam que a compreensão do conflito poderia ter lugar no que Mikkelsen \& Clegg (2017) chamam de conflito como construção social. A caracterização do conflito seria suficiente desde que houvesse a sua correspondência de como operacionalizar tal construção social. O ciclo da aprendizagem expansiva (Figura 1) em sua fase 1 de questionamento das práticas atuais, e fase 2 de análise da situação atual, são meios de alcançar a compreensão coletiva do conflito ao analisar historicamente o modo de como a comunicação das regras acontecia no passado, e de como ela acontece no presente.

Nas primeiras sessões do LM, diante do incômodo de se discutirem os distúrbios atuais e passados da atividade, há manifestações corporais que expressam possível descrença em uma tentativa de tornar o sistema de atividade da gestão de resíduos do hospital num estágio mais desenvolvido: aborrecimento, silenciamento, sonolência... Porém também ocorrem, quase que simultaneamente, proatividade, disposição para mudar e um compromisso individual para com o coletivo. Se o paradoxo entre descrença e consciência faz parte do aprendizado de alguns participantes, outros manifestam, quase que frequentemente, desacordo, discórdia, ironia, comentários provocativos, críticas sutis e tentativas de 
generalizar e relativizar o problema do seu próprio ponto de vista, sem levar em conta os diversos pontos de vista em jogo.

A perspectiva genética (Engeström, 2014; Sannino, Engeström, \& Lahikainen, 2016) de entender os fenômenos sociais em sua origem não foi uma tarefa atraente e fácil de ser conduzida. O imediatismo na busca por soluções por parte dos participantes do LM encontrou obstáculo diante da demanda pela análise genética e detalhada do passado, tal como é previsto nas primeiras sessões. Voltar ao passado não foi um exercício em que todos os participantes se sentiram confortáveis dispostos a fazer, portanto as várias manifestações percebidas são justificadas pela intenção de entender os fenômenos sociais em sua origem. Contudo é importante ressaltar: mesmo essas manifestações conflituosas, que tendem a ter um caráter negativo do ponto de vista de aprendizagem, são manifestações do poder de agência dos aprendizes, e que podem resistir às ideias e práticas em discussão (Vänninen et al., 2015).

Questões distintivas entre os trabalhadores também se manifestaram como conflitos na intervenção, de forma que alguns participantes reivindicavam atenção pelo reconhecimento de competências distintivas próprias: por idade, por tempo de trabalho no mesmo local e/ou pelo sentimento de pertencer e por ser alguém especial. A visão a partir de um pretenso mérito dialoga com conflitos manifestos na divisão hierárquica do trabalho.

O desempenho pessoal emerge entre os participantes na forma de que a impressão de experiências e conhecimentos anteriores demonstra algumas vantagens sobre os outros. Também se nota competitividade entre aqueles que sabem mais e os que sabem menos, com base na experiência de trabalho acumulada há anos no mesmo hospital. A palavra passado é frequentemente usada como estratégia dialógica para demarcar essa posição. Essas competências distintivas e o desempenho pessoal surgem em razão dos estímulos oferecidos pelas ferramentas teórico-metodológicas do LM inspiradas em Vygotsky, (1978). A análise do conflito pela via da compreensão coletiva não significa que alcançar o nível coletivo dessa análise corresponde a impedir as manifestações do nível individual. É levado em consideração aquilo que individualmente trazem nas sessões do LM, explícita ou sutilmente, nas manifestações dos trabalhadores, haja vista o entendimento teórico da zona de desenvolvimento proximal que estabelece que os aprendizes trazem consigo aprendizagens prévias de outros espaços organizacionais.

Quando os participantes discordam da organização da gestão de resíduos percebem que, como vinha sendo feita, centralizava o processo decisório nas mãos de poucas pessoas, e, frequentemente, tais decisões eram sempre relegadas aos integrantes da chamada 'alta gestão', ou seja, normalmente profissionais de nível superior. Esse questionamento, da forma como a gestão de resíduos estava organizada, colocou o grupo de aprendizes diante de uma contradição histórica, pois, ao constituírem o histórico da gestão de resíduos no hospital, perceberam que a participação na gestão de resíduos não era apenas um conflito pontual do tempo presente, mas sempre esteve presente na atividade de gestão de resíduos.

No entanto, embora o nível de participação de todos os estratos da comunidade hospitalar tenha sido questionado pelos trabalhadores, eles concordaram que também havia um conflito entre as pessoas que trabalhavam na gestão de resíduos e a necessidade de se adaptarem às legislações vigentes, que impunham a necessidade de que o hospital implementasse mudanças rápidas, de forma a adequar o seu funcionamento, impossibilitando muitas vezes que houvesse, em tempo hábil, um diálogo prévio sobre as mudanças necessárias.

Justamente por conta da agilidade demandada para adaptação às legislações cada vez mais complexas em gestão de resíduos, houve a percepção de que, com diferentes tipos de profissionais dentro do hospital, trabalhando com diferentes tipos de resíduos, também havia a circulação de diferentes tipos de instrução, favorecendo que houvesse a criação de um poder de comando e obediência que demarcava os limites entre o fazer do passado e o dever fazer diferente e mais complexo do presente.

A manutenção desse poder de comando de uns sobre os outros é manifesta principalmente sobre trabalhadores de setores operacionais, que percebem historicamente certo desprezo de alguns colegas 
pelo conhecimento que eles trazem para a atividade, especialmente dos colegas de nível superior. E ambas as categorias, tanto operacional quanto superior, percebem esse contraste da divisão hierárquica do trabalho em relação à classe médica, que não conseguiu ter uma adesão permanente à experiência de aprendizagem proposta no LM. O sentido desse conflito expressado durante a intervenção distinguia entre profissões com mais ou menos prestígio.

A experiência de aprendizagem também manifestou um conflito passado e atual referente à vivência dos trabalhadores do hospital, indicando comportamentos de passividade e agentividade. Para se referir à passividade, os trabalhadores utilizaram a palavra desresponsabilização ao ilustrar o comportamento de vários colegas de trabalho em relação à gestão de resíduos do hospital. A questão da educação também é manifesta, aliada às questões de resistência dos colegas de trabalho, porque muitos não aceitam ser aconselhados quando são vistos descartando algum material incorretamente. Alguns escolhem ignorar os conselhos ou até mesmo fingem que não estão ouvindo os colegas.

Já a agentividade se manifesta pelo fato de que, no decorrer das sessões, alguns trabalhadores decidiram por não permanecer no grupo, seja porque discordavam dos rumos que a aprendizagem estava tomando, ou ainda mesmo porque não vislumbravam uma possibilidade de mudança na atividade de gestão de resíduos. Inversamente, outros trabalhadores escolheram permanecer na experiência de aprendizagem até o fim, ainda que entre esse grupo estivessem também aqueles que pouco se manifestavam durante as sessões e, ainda, aqueles que se analisaram como mais conscientes da importância dos procedimentos individuais de descarte de resíduos.

As limitações históricas impostas pela estrutura também foram evidenciadas, porque, por mais vontade que alguém tivesse de agir para mudar o trabalho, as decisões também esbarravam nas chefias. Dessa forma, os conflitos que manifestam as contradições históricas na gestão de resíduos impõem um desafio duplo, conforme refletido por uma participante do LM: adotar novas ferramentas de trabalho sem pessoal suficiente e com recursos de que o hospital já dispõe, haja vista que, mesmo que com apoio das chefias, os procedimentos na gestão de organizações públicas, como o caso do hospital-escola, são balizados por procedimentos específicos que dificultam a possibilidade de mudança organizacional na gestão de resíduos (como a necessidade de processo de licitação para aquisição de insumos de trabalho, por exemplo).

Trazer à tona o passado por meio da compreensão da contradição em sua essência não é garantia de que haja estabilidade e controle nos comportamentos de quem está fazendo parte das sessões do LM. Estimular as reflexões sobre passado e presente, ao passo em que são construtivas do conhecimento sobre o fenômeno em análise (os procedimentos de trabalho adequados a uma boa gestão de resíduos), também são provocativas de comportamentos não previsíveis de toda a ordem, assim como os conflitos manifestados nas sessões. Dessa forma, é possível compreender que, por mais simples e operacional que se pareça uma atividade de trabalho, como aparentemente é o caso da gestão de resíduos com seus procedimentos, propor programas de treinamento e desenvolvimento no trabalho implica considerar o quanto a realidade organizacional é complexa e matizada, assim como os sujeitos que fazem parte dela.

\section{Discussão e Considerações Finais}

O objetivo deste trabalho foi evidenciar de que maneiras os conflitos perpassam uma atividade coletiva de aprendizagem. O contexto foi uma pesquisa intervencionista realizada em um hospital-escola público, que enfrenta dificuldades em relação à gestão dos resíduos de suas atividades. A experiência foi mediada por um pesquisador, apoiado por assistentes, adotando-se a metodologia de trabalho do Laboratório de Mudança, vinculada à Teoria da Atividade Histórico-Cultural.

A leitura proporcionada pelas metodologias intervencionistas da TAHC sobre o conflito organizacional vai ao encontro da constatação de Mikkelsen e Clegg (2017) de que é um caminho teoricamente limitador entender os conflitos à luz apenas de narrativas universalizantes. Não que as 
tipologias não sejam relevantes, como as inseridas em conflitos como comportamento e como instrumento na gestão. Porém, os resultados de pesquisa evidenciam que a compreensão do conflito como construção social dinâmica e histórica tem potencial de posicionar os sujeitos de uma determinada atividade de trabalho como agentes em seus contextos laborais, seja escolhendo fazer parte deles ou se omitindo.

Cabe inferir, também, a capacidade da TAHC de proporcionar teorizações conjuntivas, ou seja, que incorporam categorias da vivência humana comumente pesquisadas em separado, mas que, ao serem combinadas, permitem o enriquecimento da compreensão dessas experiências, contempladas em sua complexidade (Tsoukas, 2017). É um olhar conjuntivo para as organizações que a própria história da TAHC revela ao assumir a complexidade do conhecimento, ao incorporar pressupostos do materialismo histórico-dialético de que existe um mundo com estruturas e experiência concretas; bem como da Psicologia Histórico-Cultural russa, cuja premissa é a de que a aprendizagem é um processo mais social do que biológico, e por incorporar em seu escopo de análise tanto o individual quanto o coletivo e o social (Stetsenko, 2013).

Os conflitos principais, destacados no decorrer da intervenção, estiveram relacionados com: o novo e o velho modelo de gestão de resíduos; queixas e soluções para os distúrbios da atividade; qualidade da comunicação, processo de agentividade e passividade; reivindicação por atenção, mérito; diferentes posições hierárquicas; e as particularidades do funcionamento de uma organização pública. À luz da Teoria da Atividade, cabe compreender que esses conflitos, apesar de estarem situados no tempo presente, são manifestações de contradições históricas, ou seja, devem ser refletidos a partir de uma lógica dialética.

Vale salientar que a intervenção realizada provocou a reflexão de que a versão original do LM prevê: o apontamento e a nomeação dos conflitos na atividade em análise. Portanto, considerando o LM, como uma ferramenta para a aprendizagem organizacional (Cassandre \& Godoi, 2014; Engeström \& Sannino, 2012), reflete, por esse trabalho, que, no método original, o detalhamento e o estudo pormenorizados dos conflitos contribuem sobremaneira para sua compreensão mais ampliada, suas manifestações e suas repercussões no processo de mudança organizacional almejado.

No movimento de tentativa de expansão da atividade de gestão de resíduos para um novo modelo de trabalho com objeto (gestão de resíduos) melhor realizado, a compreensão dos sujeitos participantes sobre esses conflitos foi incisiva para que eles pudessem ter uma abrangência histórica e transversal da atividade de gestão de resíduos, entendendo que as dificuldades da gestão não são apenas questões pontuais, mas refletem uma trajetória construída através do tempo. Nesse escopo, destaca-se o papel do pesquisador intervencionista que, por meio da oferta de estímulos, como a realização de entrevistas com outros colegas de trabalho ou análises históricas sobre o passado da atividade e a construção do sistema de atividades, possibilitou aos aprendizes a construção de uma trajetória de aprendizagem na condição de autores e agentes do movimento, ainda que esse movimento fosse de resistência e oposição da parte de alguns participantes.

Em suma, em que pese o caráter negativo que possa ser inferido aos conflitos de gestão encontrados nessa pesquisa, é justamente a partir da sua compreensão que os trabalhadores do hospitalescola puderam avançar no ciclo de aprendizagem expansiva e gerar respostas, mesmo que temporárias, às contradições históricas que impedem a gestão de resíduos de ser realizada de forma efetiva. Assim, os resultados de pesquisa que foram encontrados no LM do hospital confirmam, conforme Foot (2014), o potencial da TAHC e das suas metodologias intervencionistas para compreender a complexidade das práticas sociais, reconhecendo que conflitos presentes e contradições históricas são configurações inerentes a todos os sistemas sociais.

Por outro lado, Tkachenko e Ardichvili (2017), ao apreciarem o potencial da TAHC para intervenções na área de Desenvolvimento de Recursos Humanos, reconhecem que metodologias como as do LM se afastam das perspectivas epistemológicas mais consolidadas nos periódicos acadêmicos, que permitem amplas quantificações e generalizações. Apesar disso, os autores reconhecem o valor da epistemologia da singularidade da TAHC para auxiliar os gestores de pessoas nos processos de redesign 
de trabalho e mudança organizacional. Por conta de o LM oferecer uma proposta metodológica tida como não linear, é possibilitado aos gestores dispor das ferramentas necessárias para acessar e compreender os mais diversos contextos e lugares de trabalho.

Pretende-se que sejam relatadas, em artigos futuros, as ações dos trabalhadores no período póslaboratório. Todavia, a consciência do que precisa ser feito para melhorar a gestão de resíduos do hospital-escola já foi um resultado concreto da tentativa de expansão da atividade, ao permitir que fosse vislumbrada a zona de desenvolvimento potencial (Vygotsky, 1978) da gestão de resíduos do hospital. Por fim, cabe ressaltar as possibilidades metodológicas do Laboratório de Mudança à aprendizagem organizacional, ao ser capaz de tensionar os participantes de uma dada atividade, para que os conflitos que impedem o desenvolvimento do trabalho e das pessoas possam ser revelados, de tal forma que a reflexão final seja um conhecimento histórico, coletivo e provocador, permitindo que haja contribuições ao processo de aprendizagem em curso.

\section{Referências}

Cassandre, M. P., \& Godoi, C. K. (2014). Metodologias intervencionistas da teoria da atividade histórico-cultural: Abrindo possibilidades para os estudos organizacionais [Edição Especial]. Revista Gestão Organizacional, 6, 11-23. Recuperado de http://www.academia.edu/31426312/Metodologias_intervencionistas_da_teoria_da_atividade_h ist\%C3\%B3rico-cultural_abrindo_possibilidades_para_os_estudos_organizacionais

Engeström, Y. (1987). Learning by expanding. Helsinki: Orienta-Konsultit Ou.

Engeström, Y. (2014). Learning by expanding (2nd ed.). New York: Cambridge University Press.

Engeström, Y., Kajamaa, A., \& Nummijoki, J. (2015). Double stimulation in everyday work: Critical encounters between home care workers and their elderly clients. Learning, Culture and Social Interaction, 4, 48-61. http://dx.doi.org/ 10.1016/j.lcsi.2014.07.005

Engeström, Y., Rantavuori, J., \& Kerosuo, H. (2013). Expansive learning in a library: Actions, cycles and deviations from instructional intentions. Vocations and Learning, 6(1), 81-106. http://dx.doi.org/10.1007/s12186-012-9089-6

Engeström, Y., \& Sannino, A. (2010). Studies of expansive learning: Foundations, findings and future challenges. Educational Research Review, 5(1), 1-24. http://dx.doi.org/10.1016/j.edurev.2009.12.002

Engeström, Y., \& Sannino, A. (2011). Discursive manifestations of contradictions in organizational change efforts: A methodological framework. Journal of Organizational Change Management, 24(3), 368-387. http://dx.doi.org/10.1108/09534811111132758

Engeström, Y., \& Sannino, A. (2012). Whatever happened to process theories of learning? Learning, Culture and Social Interaction, 1(1), 45-56. http://dx.doi.org/10.1016/j.lcsi.2012.03.002

Engeström, Y., \& Sannino, A. (2016). Expansive learning on the move: Insights from ongoing research. Infancia y Aprendizaje, 39(3), 401-435. http://dx.doi.org/10.1080/02103702.2016.1189119

Engeström, Y., Sannino, A., \& Virkkunen, J. (2014). On the methodological demands of formative $\begin{array}{llll}\text { interventions. Mind, } \quad \text { Culture, and } & \text { 118-128. }\end{array}$ http://dx.doi.org/10.1080/10749039.2014.891868

Foot, K. A. (2014). Cultural-historical activity theory: Exploring a theory to inform practice and research. Journal of Human Behavior in the Social Environment, 24(3), 329-347. http://dx.doi.org/10.1080/10911359.2013.831011 
Garcez, A., Duarte, R., \& Eisenberg, Z. (2011). Produção e análise de videogravações em pesquisas qualitativas. Educação e Pesquisa, 37(2), 249-262. http://dx.doi.org/10.1590/S151797022011000200003

Giddens, A., \& Sutton, P. W. (2016). Conceitos essenciais de sociologia. São Paulo: Unesp.

González Rey, F. L. (2005). Pesquisa qualitativa e subjetividade: Os processos de construção da informação. São Paulo: Thomson Learning.

Haapasaari, A., Engeström, Y., \& Kerosuo, H. (2016). The emergence of learners' transformative agency in a Change Laboratory intervention. Journal of Education and Work, 29(2), 232-262. http://dx.doi.org/10.1080/13639080.2014.900168

Heath, C., Hindmarsh, J., \& Luff, P. (2010). Video in qualitative research. Thousand Oaks: Sage Publications.

Kaatrakoski, H., Littlejohn, A. \& Hood, N. (2017). Learning challenges in higher education: An analysis of contradictions within Open Educational Practice. Higher Education, 74(4), 599-615. http://dx.doi.org/10.1007/s10734-016-0067-z

Laitinen, A., Sannino, A., \& Engeström, Y. (2016). From controlled experiments to formative interventions in studies of agency: Methodological considerations [Edição Especial]. Educação, 39, s14-s23. http://dx.doi.org/10.15448/1981-2582.2016.s.24321

Levine, D. (2015). Revisiting Georg Simmel. Sociologia \& Antropologia, 5(1), 31-52. http://dx.doi.org/10.1590/2238-38752015v512

Loizos, P. (2008). Vídeo, filme e fotografias como documentos de pesquisa. I M. W. Bauer \& G. Gaskell (Eds.), Pesquisa qualitativa com texto, imagem e som: Um manual prático (pp. 137-155). Petrópolis: Vozes.

Marx, K. (2013). O capital - livro I. São Paulo: Boitempo.

Mikkelsen, E. N., \& Clegg, S. (2017, June 29). Conceptions of conflict in organizational conflict research: Toward critical reflexivity. Journal of Management Inquiry (ahead of print). http://dx.doi.org/10.1177/1056492617716774

Pozzebon, M., \& Petrini, M. (2013). Critérios para condução e avaliação de pesquisas qualitativas de natureza crítico-interpretativa. In A. R. W. Takahashi (Org.), Pesquisa qualitativa em Administração: Fundamentos, métodos e usos no Brasil (pp. 51-72). São Paulo: Atlas.

Querol, M. A. P., Cassandre, M. P., \& Bulgacov, Y. L. M. (2014). Teoria da atividade: Contribuições conceituais e metodológicas para o estudo da aprendizagem organizacional. Gestão \& Produção, 21(2), 405-416. http://dx.doi.org/10.1590/0104-530X351

Sannino, A. (2015). The principle of double stimulation: A path to volitional action. Learning, Culture and Social Interaction, 6, 1-15. http://dx.doi.org/10.1016/j.lcsi.2015.01.001

Sannino, A., \& Engeström, Y. (2017). Co-generation of societally impactful knowledge in Change Laboratories. Management Learning, 48(1), 80-96. http://dx.doi.org/10.1177/1350507616671285

Sannino, A., Engeström, Y., \& Lahikainen, J. (2016). The dialectics of authoring expansive learning: Tracing the long tail of a Change Laboratory, Journal of Workplace Learning, 28(4), .245-262. https://doi.org/10.1108/JWL-01-2016-0003 
Sannino, A., Engeström, Y., \& Lemos, M. (2016). Formative interventions for expansive learning and transformative agency. Journal of the Learning Sciences, 25(4), 599-633. http://dx.doi.org/10.1080/10508406.2016.1204547

Sannino, A., \& Laitinen, A. (2015). Double stimulation in the waiting experiment: Testing a vygotskian model of the emergence of volitional action. Learning, Culture and Social Interaction, 4, 4-18. http://dx.doi.org/10.1016/j.lcsi.2014.07.002

Silva, A. B., \& Rossetto, C. R. (2010). Os conflitos entre a prática gerencial e as relações em família: Uma abordagem complexa e multidimensional. Revista de Administração Contemporânea, 14(1), 40-60. Recuperado de http://www.scielo.br/pdf/rac/v14n1/04.pdf. https://dx.doi.org/10.1590/S1415-65552010000100004

Silva, A. R. L., Junquilho, G. S., \& Carrieri, A. P. (2008). Políticas de RH: Instrumentos de consenso e ambiguidade. Revista de Administração Contemporânea, 12(1), 11-34. http://dx.doi.org/10.1590/S1415-65552008000100002

Simmel, G. (1971). Conflict. In D. Levine (Ed.), Georg Simmel: On individuality and social forms (pp. 70-95). Chicago: The University of Chicago Press.

Stetsenko, A. (2013). The challenge of individuality in cultural-historical activity theory: Collectividual dialectics from a transformative activist stance. Outlines - Critical Practice Studies, 14(2), 7-28.

Tkachenko, O., \& Ardichvili, A. (2017). Cultural-historical activity theory's relevance to HRD: A review and application. Human Resource Development Review, 16(2), 135-157. http://dx.doi.org/10.1177/1534484317696717

Tsoukas, H. (2017). Don't simplify, complexify: From disjunctive to conjunctive theorizing in organization and management studies. Journal of Management Studies, 54(2), 132-153. http://dx.doi.org/10.1111/joms.12219

Vänninen, I., Querol, M. P., \& Engeström, Y. (2015). Generating transformative agency among horticultural producers: An activity-theoretical approach to transforming integrated pest management. Agricultural Systems, 139, 38-49. http://dx.doi.org/10.1016/j.agsy.2015.06.003

Virkkunen, J., \& Newnham, D. S. (2015). O laboratório de mudança: Uma ferramenta de desenvolvimento colaborativo para o trabalho e educação. Belo Horizonte: Fabrefactum.

Vygotsky, L. (1978). Interaction between learning and development. In M. Cole, V. John-Steiner, S. Scribner, \& E. Souberman (Ed.), Mind in society (pp. 79-91). Cambridge, Cambridge University Press.

Weber, M. (1978). Economy and society: An outline of interpretive sociology. Berkeley: University of California Press.

\section{Dados dos Autores}

Maurício Donavan Rodrigues Paniza

Av. Nove de Julho, 2029, 01313-902, São Paulo, SP, Brasil. E-mail: mauriciopaniza @ gmail.com. https://orcid.org/0000-00016544-9640

Marcio Pascoal Cassandre

Av. Colombo, 5.790, Bloco C-23, 87020-900, Maringá, PR, Brasil. E-mail: mcassandre@ hotmail.com. https://orcid.org/00000001-9415-4315

Carine Maria Senger

Av. Minas Gerais, 5021, 86800-970, Apucarana, PR, Brasil. E-mail: carine.senger@gmail.com

RAC, Rio de Janeiro, v. 22, n. 2, art. 6, pp. 271-290, março/abril 2018

www.anpad.org.br/rac 